\title{
APOSTATIC SELECTION BY STICKLEBACKS UPON A DIMORPHIC PREY
}

\author{
MARY MASKELL, DAVID T. PARKIN* and ERIC VERSPOOR \\ Department of Genetics, University of Nottingham, University Park, Nottingham NG7 2RD
}

Received 11.x.76

\begin{abstract}
SUMMARY
Asellus aquaticus shows continuous variation in phenotype from white through yellow and brown to black. An artificial polymorphism was created by choosing the palest and darkest individuals, and these showed no preference for their background when offered a choice of black or white substrate. Sticklebacks exhibited no differential predation when the two phenotypes were offered to them at equal frequency. However, when phenotypes were offered in frequencies of $4: 1$, the sticklebacks chose an excess of the commoner form whether dark or light. The use of the stickleback-Asellus system in analysing density-dependent and frequency-dependent predation is discussed.
\end{abstract}

\section{INTRODUGTION}

Aposxaxic selection has attracted a considerable amount of attention since Clarke (1962) first coined the term and reminded the scientific community that frequency-dependent predation could be responsible for the maintenance of visual polymorphisms in prey species. The theory is attractive for it is intellectually satisfying: common forms are predated to excess because predators encounter them more frequently and develop a specific image for their phenotype. Overpredation results in a change in the relative frequencies of the phenotypes and a correlated change in the patterns of predation. Stable equilibria arise at positions that depend upon the relative visibility of the prey phenotypes, their behaviour and the methods of hunting of the predators.

Theoretical studies have been paralleled by analyses of the experimental basis of the phenomenon. These have usually related to wild predators and artificial prey (e.g. Allen and Clarke, 1968; Allen, 1972; etc.). A few experiments have been undertaken that involved live prey, but these are usually more difficult to "stage-manage". Clarke (1962) re-analysed some data of Popham (1941, 1942) that related to the predation of a fish (Scardinius erithophthalmus) upon corixid bugs in aquarium tanks. There was good evidence of an overpredation of the common form, but a problem with the system is that bugs of the wrong colour on any substrate are more restless and consequently are more readily eaten. To avoid this difficulty Smith (1967) used minnows and fed them upon small pieces of coloured paste, but was unable to obtain consistent results, nor to detect either visual selection for crypsis or frequency-dependent predation. He was able to train his fish to predate a particular form, however, thus establishing a learning behaviour for food, which is a prerequisite for apostatic selection.

* Author to whom requests for reprints should be sent. 
During a study of enzymic variation in the freshwater louse, Asellus aquaticus, one of us (E. V.) noticed that there was considerable phenotypic variation in some populations. We decided to examine the suitability of this material for a study of apostatic selection.

\section{Materials AND METHODS}

Asellus aquaticus is a freshwater isopod and is widely distributed in the River Trent and its tributaries in the English Midlands. It forms an important food resource for fish (Birstein, 1964; Bergund, 1968), and laboratory experiements showed that individuals were readily eaten by sticklebacks (Gastrosteus aculeatus) coming from the same locality. $A$. aquaticus exhibits continuous phenotypic variation from white through yellow and brown to black. The genetic basis of this is not known, although some biochemical aspects have been studied by Needham and Brunet (1957).

A large sample of $A$. aquaticus was taken from the River Erewash near the sewage works at Trowell in Nottinghamshire. The sample was sorted by hand and the darkest and palest individuals were used in the following experiments. Animals measuring about $5 \mathrm{~mm}$ in overall length were chosen for experimental offering to the fish. Sticklebacks were taken from the same area so they were accustomed to feeding upon Asellus. No stickleback was used more than once in the whole series of experiments reported here.

The experimental arena consisted of an aquarium tank measuring 32 $\mathrm{cm} \times 12 \mathrm{~cm} \times 20 \mathrm{~cm}$ deep. This was filled with river water, and A. aquaticus were placed inside. In the absence of an uneven substrate, the Asellus aggregated together into a ball, and so aquarium gravel was placed on the bottom. The particules of this were approximately $3 \mathrm{~mm}$ in diameter, and ranged in colour from pale to dark brown. Early in the study, it was found that single sticklebacks took a long time to become accustomed to the tank and so they were used in pairs. The feeding rate was too low for continual observation to be a practical proposition, and, also, if they detected any movement outside the tank, feeding stopped. The aquarium was therefore surrounded by cardboard to minimise disturbance. The fish were left for 3 hours with low illumination from above. At the end of this period, the sticklebacks were removed and the gravel was sifted to remove any surviving Asellus. As a result of this procedure, it was not possible to control the total number of Asellus eaten in any single experiment.

\section{Results}

\section{(i) Background preference}

The main experiments reported here concern the response of sticklebacks to a polymorphic prey. If that prey selects a substrate upon which it is cryptic, the results will be more difficult to analyse. A preliminary study was made to test for this.

A standard aquarium tank was placed on a chequerboard pattern of black and white squares. Because of the "clumping" behaviour of the Asellus, the bottom of the tank was covered with small clear glass beads which are normally used to prevent " bumping " of boiling solutions. These 
provided a transparent substrate to which the animals could cling. The chequerboard showed through as areas of light and dark.

Four replicates of $20 \mathrm{~A}$. aquaticus each were placed under these conditions for a period of 1 hour. Table 1 shows that there was no evidence of differential settlement by the light or dark individuals. There is thus no evidence of background selection.

TABle 1

Settling positions of 10 pale and 10 dark individual Asellus aquaticus given a chequerboard of dark and light substrates. In all four replicates, there is no evidence of preference

\begin{tabular}{cccccc} 
Replicate & \multicolumn{2}{c}{ Pale Asellus } & $\overbrace{\text { Dark ground }}^{2}$ Dark Asellus \\
A & Dark ground & Light ground & & 4 \\
B & 5 & 6 & 5 & 4 \\
C & 6 & 5 & 4 & 5 \\
D & 6 & 5 & 4 & 7
\end{tabular}

(ii) Predation

Three series of predation experiments were performed. In each experiment a total of 40 Asellus was placed in the tank. Series A involved equal numbers of pale and dark individuals. Series B utilised 10 pales and 40 darks, and Series $\mathrm{C}$ the reverse of this. Six replicates were made in Series A, and nine in each of Series B and Series C.

The number of each form of Asellus disappearing during the 3 hours of the experiment, and presumably eaten by one or other of the two sticklebacks is recorded in tables $2 \mathrm{~A}, 2 \mathrm{~B}$ and $2 \mathrm{C}$ for the three series. Each of these sets of results is a three-dimensional contingency table, and can be analysed using chi-square.

The method of analysis which we have used is the multidimensional contingency table system described so lucidly by Fienberg (1970) and programmed into General Linear Interactive Modelling (GLIM) by Nelder (1974). The principle of this is to compare the observed data with the predictions of a model made successively more complex by a series of components based upon the marginals. The reduction in magnitude of the goodness-of-fit chi-square reflects the improvement of the model in describing the observations. The results of this method of analysis are given in tables $3 \mathrm{~A}, 3 \mathrm{~B}$ and $3 \mathrm{C}$. The analysis of Series A will be described in detail, to make the method clear; only the salient points will be selected from the other two series.

The first four lines of table $3 \mathrm{~A}$ show the results of fitting the essential parameters to the model. Model I is trivial, comparing each cell in the table with an average for the whole experiment--in this case 10.0 as there were 240 Asellus in the experiment, and 24 cells in the table. The agreement between the observed and expected results is poor, as reflected by $\chi_{23}^{2}=88.4$ $(\mathrm{P}<<0.001)$. Model II allows for the possibility that the replicates may include different numbers of Asellus, and Model III allows for different numbers of the two phenotypes. The experiments were designed in such a way that the replicates were equal in size, and Series A contained equal numbers of pale and dark Asellus. There is thus no change in the values of the expected cell numbers, and the $\chi^{2}$ does not change---although the 
number of degrees of freedom decreases because we have fitted additional data. Model IV incorporates a mortality component. Models I-III assumed an equal number of animals were eaten or survived. This is clearly not so, and allowance for it significantly improves the goodness-of-fit. Chi-square is reduced by 79.3 with only one degree of freedom.

We have now considered the least interesting aspects of the experiment. All the parameters we have included in the model are components of experimental design, and can be altered more-or-less at will. The secondorder interactions that we will now consider are biologically more relevant.

TABLE 2A

Results of offering 20 pale Asellus and 20 dark to two sticklebacks. Six replicates

\begin{tabular}{ccccc} 
& \multicolumn{2}{c}{ Pale } & & \multicolumn{2}{c}{ Dark } \\
Rep. & Eaten & Left & & Left \\
1 & 7 & 13 & 5 & 15 \\
2 & 3 & 17 & 3 & 17 \\
3 & 4 & 16 & 3 & 17 \\
4 & 5 & 15 & 6 & 14 \\
5 & 5 & 15 & 7 & 13 \\
6 & 3 & 17 & 2 & 18
\end{tabular}

Table 2B

Results of offering 40 pale and 10 dark Asellus aquaticus to two sticklebacks. Nine replicates

\begin{tabular}{|c|c|c|c|c|}
\hline \multirow[b]{2}{*}{ Rep. } & \multicolumn{2}{|c|}{ Pale } & \multicolumn{2}{|c|}{ Dark } \\
\hline & Eaten & Left & Eaten & Left \\
\hline 1 & 9 & 31 & 1 & 9 \\
\hline 2 & 8 & 32 & 0 & 10 \\
\hline 3 & 9 & 31 & 0 & 10 \\
\hline 4 & 6 & 34 & 1 & 9 \\
\hline 5 & 16 & 24 & 4 & 6 \\
\hline 6 & 10 & 30 & 0 & 10 \\
\hline 7 & 10 & 30 & 0 & 10 \\
\hline 8 & 12 & 28 & 0 & 10 \\
\hline 9 & 13 & 27 & 2 & 8 \\
\hline
\end{tabular}

TABLE 2C

Reiults of offering 10 pale and 40 dark Asellus aquaticus to two sticklebacks. Nine replicates

\begin{tabular}{ccccc} 
Rep. & \multicolumn{2}{c}{ Pale } & \multicolumn{3}{c}{ Dark } & $\overbrace{\text { Eaten }}^{\text {Left }}$ \\
1 & 0 & 10 & 3 & 37 \\
2 & 2 & 8 & 8 & 32 \\
3 & 0 & 10 & 9 & 31 \\
4 & 2 & 8 & 15 & 25 \\
5 & 1 & 9 & 8 & 32 \\
6 & 1 & 9 & 13 & 27 \\
7 & 2 & 8 & 14 & 26 \\
8 & 1 & 9 & 10 & 30 \\
9 & 2 & 8 & 11 & 29
\end{tabular}


TABLE 3A

Results of analysis of data from $20: 20$ predation experiment (for details see text)

Improvement

\begin{tabular}{rlrrrrr}
\multicolumn{1}{c}{ Model } & $\chi^{2}$ & d.f. & $\chi^{2}$ & d.f. & P \\
I & Basic & $88 \cdot 4$ & 23 & & & \\
II & + Reps. & $88 \cdot 4$ & 18 & 0 & 5 & NS \\
III & + Phens. & $88 \cdot 4$ & 17 & 0 & 1 & NS \\
IV & + Mort. & $9 \cdot 1$ & 16 & $79 \cdot 3$ & 1 & $* * *$ \\
V & + Rep. Phen. & $9 \cdot 1$ & 11 & 0 & 5 & NS \\
VI & + Rep. Mort. & $1 \cdot 5$ & 6 & $7 \cdot 6$ & 5 & NS \\
VII & + Phen. Mort. & $1 \cdot 4$ & 5 & $0 \cdot 1$ & 1 & NS
\end{tabular}

TABLE 3B

Results of analysis of " dark rare" predation experiments (see text for details)

\begin{tabular}{|c|c|c|c|c|c|c|}
\hline & & & & & veme & \\
\hline & Model & $x^{2}$ & d.f. & $x^{2}$ & d.f. & $\mathrm{P}$ \\
\hline I & Basic & $358 \cdot 5$ & 35 & & & \\
\hline II & + Reps. & 358.5 & 27 & 0 & 8 & NS \\
\hline III & +Phens. & $185 \cdot 1$ & 26 & $173 \cdot 4$ & 1 & $* * *$ \\
\hline IV & + Mort. & 40.5 & 25 & 144.6 & i & $* * *$ \\
\hline $\mathrm{V}$ & + Rep. Phen. & $40 \cdot 5$ & 17 & 0 & 8 & NS \\
\hline VI & + Rep. Mort. & $26 \cdot 5$ & 9 & $14 \cdot 0$ & 8 & NS \\
\hline VII & + Phen. Mort. & $12 \cdot 1$ & 8 & $14 \cdot 4$ & 1 & $* * *$ \\
\hline
\end{tabular}

TABLE 3C

Results of analysis of " pale rare" predation experiment (see text for details)

\begin{tabular}{|c|c|c|c|c|c|c|}
\hline & & & & $\mathrm{Im}$ & veme & \\
\hline & Model & $x^{2}$ & d.f. & $\chi^{2}$ & d.f. & $P$ \\
\hline I & Basic & $345 \cdot 5$ & 35 & & & \\
\hline II & + Reps. & $345 \cdot 5$ & 27 & 0 & 8 & NS \\
\hline III & + Phens. & $173 \cdot 1$ & 26 & $173 \cdot 4$ & 1 & $* * *$ \\
\hline IV & + Mort. & $30 \cdot 9$ & 25 & $142 \cdot 2$ & 1 & $* * *$ \\
\hline V & + Rep. Phen. & $30 \cdot 9$ & 17 & 0 & 8 & NS \\
\hline VI & + Rep. Mort. & $12 \cdot 3$ & 9 & $18 \cdot 6$ & 8 & $*$ \\
\hline VII & + Phen. Mort. & $4 \cdot 3$ & 8 & 8.0 & 1 & $* * *$ \\
\hline
\end{tabular}

There are three of these effects and they can be added in any order. We have included them in an arbitrary sequence that leaves the most interesting results until last. This seems to be the most valid method, although the results remain essentially the same whatever the order.

Model $\mathrm{V}$ allows for differences between the number of each phenotype in the various replicates. Again, as a matter of experimental design, 20 of each phenotype were used in every replicate of Series A, so this model does not improve the fit to the data. Model VI considers the effects of different numbers of Asellus being eaten in the six replicates. Theoretically, this is also under our control, but we did not watch the sticklebacks feeding, so it was not possible to ensure that a constant number of Asellus were taken in each experiment. Allowing for this difference improves the fit by $\chi^{2}{ }_{15}=7 \cdot 6$, which is not significant, so we can infer that our levels of predation did not vary much within Series A. Model VII includes differences in the level of 
predation upon the two phenoytpes. Again, the improvement in fit is not significant so we can infer from this that the sticklebacks were not predating the two phenotypes differentially. This is the biologically important result, for it implies that the sticklebacks do not differentiate between the two forms of Asellus on this background at this density, when they are presented in equal frequency. The value of $\chi^{2}{ }_{(5)}=1 \cdot 4$ given by Model VII tells us the third-order interaction between replicates, phenotypes and predation is not significant. Thus there is no difference in the response of the predators in the six replicates.

Table 3B lists the results of a similar analysis upon the data of table $2 \mathrm{~B}$. There are two trivial significances in table $3 \mathrm{~B}$ and one of biological importance. The first two merely tell us that, when we allow for different phenotype frequencies, and different levels of predation, we get a better fit to the results. The third result is more important for it stems from including differential mortality upon the two phenotypes. In fact, a significant excess of the pale phenotype have been removed from the aquarium.

Table $3 \mathrm{C}$ shows that the data in table $2 \mathrm{C}$ are in substantial agreement with this, except that overpredation has occurred on the dark phenotype. There is additionally evidence of a slight difference in the number of Asellus eaten in the nine replicates. This unfortunately stems from our being unable to control the predation rate more closely. It does not affect the validity of the other results. In neither of Series B or C is there any evidence of different predation patterns between the nine replicates.

\section{Discussion}

Studies upon the responses of predators to a polymorphic prey have often been bedevilled by heterogeneity in the behaviour of different individuals when offered a choice situation. For example, Allen and Clarke (1968) offered wild birds a choice of two colours of artificial prey. They found that some birds had a " preference" for one colour, while others of the same species took more of the other. Such a result could have stemmed from an innate preference upon the part of the bird. Alternatively, it could have been due to a period of pre-conditioning when the bird had habitually been feeding upon prey of one or other colour. Furthermore, there is some evidence that preferences may differ between species (Allen and Clarke, 1968), and with season as well (Dr H. A. Ford, personal communication).

The experimental situation that we have used is simple and easily replicated. The fish are taking a natural prey although they are being offered extreme phenotypes from a continuous distribution. Because of the limited time available for this study, we have used only three frequencies of prey phenotype, and offered them at a single density. Nevertheless, the simplicity of the system has borne fruit. We have clear evidence of an overpredation of the commoner phenotype-apostatic selection.

We do not pretend that our results have any bearing upon the cause of phenotypic variation in natural populations of Asellus aquaticus. We have created an artificially polymorphic situation and studied the effects of predation upon it. We find that under such simple conditions, highly repeatable results can be obtained, and a more careful monitoring of predation rate would have eliminated all heterogeneity from the results: such a 
situation would be particularly valuable in attempts to disentangle the currently vexed problems associated with the interaction between density and morph frequency in predation behaviour.

Acknowledgments.-We would like to thank our colleagues in the Genetics Department at the University of Nottingham for their comments and advice during the execution of this study, and particularly Professor B. C. Clarke for the facilities that he has provided. D. T. Parkin acknowledges the Science Research Council for a Research Grant, and E. Verspoor is financed from the Allied Breweries' Bequest to the University of Nottingham.

\section{REFERENCES}

ALlen, J. A. 1972. Evidence for stabilising and apostatic selection by wild blackbirds. Nature, 237, 348-349.

Allen, J. A. AND CLARKE, B. C. 1968. Evidence for apostatic selection by wild passerines. Nature, 220, 501-502.

BERGUND, T. 1968. The influence of predation by brown trout on Asellus in a pond. Rep. Inst. Freshw. Res., 48, 77-101.

Birstein, y. A. 1964. Freshwater isopods: crustacea. Israel Program for Scientific Translation, $V I I$, no. 5 .

CLARKE, B. 1962. Balanced polymorphism and the diversity of sympatric species. Publs. Syst. Ass., No. 4, 47-70.

FIENBERG, S. E. 1970. The analysis of multidimensional contingency tables. Ecology, 51, 419-433.

NEEDHAM, A. E., AND BRUNET, P. C. J. 1957. The integumental pigment of Asellus aquaticus. Experientia, 13, 207-209.

NELDER, J. A. 1974. General linear interactive modelling. Numerical Algorithms Group, Oxford.

POPHAM, E. J. 1941. The variation in the colour of certain species of Arctocorisa (Hemiptera, Corixidae) and its significance. Proc. zool. Soc. Lond. A, 111, 135-172.

POPHAM, E. J. 1942. Further experimental studies on the selective action of predators. Proc. zool. Soc. Lond. A, 112, 105-117.

smith, J. M. N. 1967. Experiments on the food selection of the minnow (Phoxinus phoxinus L.). B.Sc. Thesis, Edinburgh University. 